\title{
Zoledronate-induced $S$ phase arrest and apoptosis accompanied by DNA damage and activation of the ATM/Chk1/cdc25 pathway in human osteosarcoma cells
}

\author{
TOYOTAKA IGUCHI ${ }^{1}$, YOSHITAKA MIYAKAWA ${ }^{1}$, KAORI SAITO $^{1}$, CHIKA NAKABAYASHI $^{1}$, \\ MAKOTO NAKANISHI $^{3}$, HIDEYUKI SAYA ${ }^{2}$, YASUO IKEDA ${ }^{1}$ and MASAHIRO KIZAKI ${ }^{1}$ \\ ${ }^{1}$ Division of Hematology, Department of Internal Medicine, ${ }^{2}$ Division of Gene Regulation, Institute for Advanced \\ Medical Research, Keio University School of Medicine, 35 Shinanomachi, Shinjuku, Tokyo 160-8582; \\ ${ }^{3}$ Department of Biochemistry, Nagoya City University Medical School, Nagoya, Aichi 467-8601, Japan
}

Received March 26, 2007; Accepted May 21, 2007

\begin{abstract}
Osteosarcoma is one of the most common primary malignant tumors of the bone in children and adolescents. Some patients continue to have a poor prognosis, as they have metastatic disease and frequent occurrence of drug resistance. Zoledronate is a nitrogen-containing bisphosphonate that has been used for the treatment of hypercalcemia and bone metastasis, because it induces apoptosis in osteoclasts and tumor cells by inhibiting the isoprenylation of intracellular small $\mathrm{G}$ proteins. Besides inhibiting isoprenylation, little is known about the manner by which bisphosphonates inhibit cellular proliferation and induce apoptosis. This prompted us to investigate the inhibitory effects of zoledronate in human osteosarcoma cell lines, HOS and MG63. HOS cells accumulated in S phase around $6 \mathrm{~h}$ after treatment with $10 \mu \mathrm{M}$ zoledronate, followed by apoptosis. When HOS cells were treated with zoledronate, ATM kinase and its substrate, check-point kinase (Chk)1, were phosphorylated. Zoledronate also induced phosphorylation of cdc25a (Thr506) in HOS cells, which is a substrate of Chk1, and its phosphorylation is known to be critical for $\mathrm{S}$ phase arrest. Following treatment with zoledronate, phosphorylated histone H2AX $(\gamma-\mathrm{H} 2 \mathrm{AX})$ displayed patterns of nuclear foci in HOS cells. As $\gamma$-H2AX accumulates at dsDNA breaks, these results demonstrate that zoledronate induced DNA damage and S phase arrest, accompanied by activation of the ATM/Chk1/cdc 25 pathway in a human osteosarcoma cell line.
\end{abstract}

Correspondence to: Dr Yoshitaka Miyakawa, Division of Hematology, Department of Internal Medicine, Keio University School of Medicine, 35 Shinanomachi, Shinjuku-ku, Tokyo 160-8582, Japan E-mail: yoshi@sc.itc.keio.ac.jp

Key words: ATM, check-point kinase, osteosarcoma, S phase arrest, zoledronate

\section{Introduction}

Osteosarcoma is one of the most common primary malignant tumors of the bone in children and adolescents $(1,2)$. The long-term survival of patients with osteosarcoma has dramatically improved from 10 to nearly $80 \%$ within the last few decades, because of multiple chemotherapy $(1,2)$. However, some patients continue to have a poor prognosis, as they have metastatic disease, particularly osteolytic bone metastatis. In addition, the frequent acquisition of drugresistant phenotypes and the occurrence of second malignancies after chemotherapy are considered to be serious problems $(1,3)$. This prompted us to develop new approaches for the treatment of osteosarcoma.

Bisphosphonates are the standard therapy for tumorassociated hypercalcemia and osteoporosis, and have recently been reported to have clinical use in palliative treatment of bone metastasis, because of their potential to prevent osteoclast-mediated bone resorption $(4,5)$. It has been reported that bisphosphonates can induce apoptosis in various human tumor cell lines, such as myeloma $(6,7)$, breast cancer $(8)$, prostate cancer (9) and pancreatic cancer (10). Bisphosphonates also have anti-tumor activity, reduce skeletal tumor burden, and inhibit formation of bone metastasis in animal models (5,11-13). Several mechanisms have been proposed to explain these observations. Bisphosphonates induce apoptosis through inhibiting the mevalonate pathway in osteoclasts. In addition to their inhibitory effects on osteoclasts, there are new extensive data demonstrating that bisphosphonates can directly act on tumor cells; they inhibit tumor cell adhesion to mineralized bone (14), as well as tumor cell invasion (15) and proliferation $(16,17)$. It has also been reported that bisphosphonates can stimulate cytotoxicity of $\gamma \delta \mathrm{T}$ cells against tumor cells $(18,19)$. Previously, we have reported that nitrogen-containing bisphosphonates induce $\mathrm{S}$ phase cell cycle arrest and apoptosis in myeloma cell lines, by inhibiting the synthesis of geranylgeranyl diphosphate (GGPP), which is necessary for isoprenylation of small $G$ protein (7). Not only tumor cells, but also normal osteoclasts require geranylgeranylation of intra- 
cellular proteins to maintain their function $(20,21)$. In this study, we demonstrated that zoledronate inhibited proliferation and induced apoptosis in human osteosarcoma cell lines, HOS and MG63. Zoledronate induced DNA damage and phosphorylation of ATM, check-point kinase (Chk) 1 and cdc25 in these cells. These observations are helpful for understanding the mechanisms of the anti-tumor effect of bisphosphonates in osteosarcoma cells, and we expect that zoledronate has potential for future clinical development as an anti-cancer drug for osteosarcoma.

\section{Materials and methods}

Reagents. Zoledronate (MW 399.5) was kindly provided by Novartis Pharma (Basel, Switzerland). Antibodies were purchased from the following manufactures: ATM (Upstate Biotechnology, Lake Placid, NY, USA), ATR (Abcam, Cambridge, UK), Chk1 (G-4), Chk2 (A-12), cdc25a (F-6), non-isoprenylated Rap1A and actin (Santa Cruz, San Jose, CA, USA), Phospho ATM (Rockland, Gilbertsville, PA, USA), phospho Chk1 (Ser345), phospho Chk2 (Thr68), phospho cdc2 (Tyr15), phospho cdc25a (Thr506), phospho cdc25c (Ser216) (Cell Signaling Technologies, Beverly, MA, USA), cdc2 and cdc25c (BD Biosciences, San Jose, CA, USA), phospho histone H2AX ( $\gamma$-H2AX) (Trevigen, Gaithersburg, MD, USA). Phospho-ATM/ATR substrate antibody (Cell Signaling no. 2581) detects phosphorylated serine or threonine in the $\mathrm{S}^{*} / \mathrm{T}^{*} \mathrm{Q}$ motif, which is an essential requirement for the substrates of ATM/ATR. Geranylgeraniol (GGOH) was purchased from Sigma (St. Louis, MO, USA).

Cell culture. The human osteosarcoma cell lines HOS and MG63 were obtained from ATCC (Rockville, MD, USA). The cells were maintained in Dulbecco's modified Eagle's medium (DMEM) (Sigma), supplemented with 10\% heatinactivated fetal bovine serum (FBS) (Life Technologies, Rockville, MD, USA), $100 \mu \mathrm{g} / \mathrm{ml}$ streptomycin and $100 \mathrm{U} / \mathrm{ml}$ penicillin $\mathrm{G}$ (Invitrogen, Carlsbad, CA, USA) in a humidified atmosphere of $5 \% \mathrm{CO}_{2}$ and $95 \%$ air at $37^{\circ} \mathrm{C}$.

Cell proliferation assay. Cells were suspended at a final concentration of $10^{4}$ cells $/ \mathrm{ml}$ in DMEM containing 10\% FBS in 96-well plates in triplicate. Reagents were added to each well in various combinations and incubated for 2 days at $37^{\circ} \mathrm{C}$ in $5 \% \mathrm{CO}_{2}$. Cellular proliferation was measured by the MTS assay kit (Promega Corporation, Madison, WI, USA).

Flow cytometry. Flow cytometry of the cell cycle and apoptosis was performed as previously described $(22,23)$. Osteosarcoma cells were incubated with or without $10 \mu \mathrm{M}$ zoledronate for the indicated times, followed by cell cycle analysis. Apoptosis was analyzed using annexin V-FITC antibody (BD Biosciences) and propidium iodide (PI). Annexin V(+)/PI(-) and annexin $\mathrm{V}(+) / \mathrm{PI}(+)$ represented the cells in early apoptosis and late apoptosis/necrosis, respectively.

Double thymidine block and cell cycle analysis by flow cytometry. HOS cells were innoculated at $10^{5}$ cells per $25 \mathrm{~cm}^{2}$ flask and cultured in DMEM containing 10\% FBS with $2 \mathrm{mM}$ thymidine for $16 \mathrm{~h}$ (first thymidine block). The cells were washed twice with warm PBS and cultured in DMEM containing $10 \%$ FBS for $8 \mathrm{~h}$ (first thymidine release). Twentyfour hours after the first thymidine block, cells were cultured with $2 \mathrm{mM}$ thymidine (second thymidine block) for $16 \mathrm{~h}$. After washing twice with warm PBS (second thymidine release), cells were cultured in DMEM containing 10\% FBS with or without $10 \mu \mathrm{M}$ zoledronate. After being cultured for the indicated time, the cells were labeled with bromodeoxyuridine $(\mathrm{BrdU})$ for $1 \mathrm{~h}$. After incubation at room temperature in the dark, the cell cycle of HOS cells was analyzed with FITC-conjugated anti-BrdU antibody and PI by FACS Calibur (BD Biosciences).

Western blotting. Human osteosarcoma cells were cultured with or without zoledronate at the indicated concentrations for various lengths of time, washed once with ice-cold PBS, and lysed in a buffer composed of $20 \mathrm{mM}$ Tris/ $\mathrm{HCl}$ (pH 8.0), $137 \mathrm{mM} \mathrm{NaCl}, 1.5 \mathrm{mM} \mathrm{MgCl}_{2}, 1 \mathrm{mM}$ EGTA, $10 \%$ glycerol, $100 \mathrm{mM} \mathrm{NaF}$, and $1 \%$ Triton X-100 (24). The protein concentration of lysates was measured by the Protein DC Assay kit (Bio-Rad, Hercules, CA, USA). Twenty micrograms of protein lysate were suspended in $2 \mathrm{X}$ gel electrophoresis loading buffer, and heated at $90^{\circ} \mathrm{C}$ for $5 \mathrm{~min}$. The lysates were subjected to SDS-PAGE and Western blotting. ECL Western blotting detection reagents were used to visualize the target protein (Amersham Biosciences, Piscataway, NJ, USA).

RNA interference (siRNA). Small interfering RNA (siRNA) of ATM and ATR was purchased from B-Bridge International (Sunnyvale, CA, USA). Human osteosarcoma cells were cultured in DMEM with 10\% FBS. Just before transfection, the cells were washed twice with PBS and plated in 6-well plates at $1 \times 10^{4}$ cells per well in $2 \mathrm{ml}$ serum-free DMEM. Transfection of osteosarcoma cells was performed with Lipofectamine 2000 reagent (Invitrogen), following the manufacturer's instructions. The cells were subjected to Western blotting and cell cycle analysis $48 \mathrm{~h}$ after transfection.

Immunofluorescence microscopy. HOS cells were cultured with or without $10 \mu \mathrm{M}$ zoledronate for $24 \mathrm{~h}$. Cells were placed immediately in $100 \%$ methanol or $2 \%$ paraformaldehyde at room temperature for $2 \mathrm{~min}$ to fix the cells. Anti-phospho $\mathrm{H} 2 \mathrm{AX}$ at $10 \mu \mathrm{g} / \mathrm{ml}$ was added to each slide, which was incubated for $2 \mathrm{~h}$. Slides were washed in PBS three times each for $5 \mathrm{~min}$, and secondary antibody conjugated with Alexa Fluor 488 (1:200; Molecular Probes, Eugene, OR, USA) was added to slides for $60 \mathrm{~min}$. Slides were washed in PBS three times for $5 \mathrm{~min}$, covered with anti-fading medium with PI, Vectashield (Vector laboratories, Burlingame, CA, USA). Images were taken using a confocal microscope, LSM510 (Carl Zeiss, Wetzlar, Germany).

Statistical analysis. Statistical difference was determined by Student's t-test. The data are presented as the mean \pm SD. $\mathrm{P}<0.05$ was considered significant.

\section{Results}

Inhibition of human osteosarcoma cell proliferation by zoledronate. Zoledronate inhibited the proliferation of human 


\section{A HOS cells}

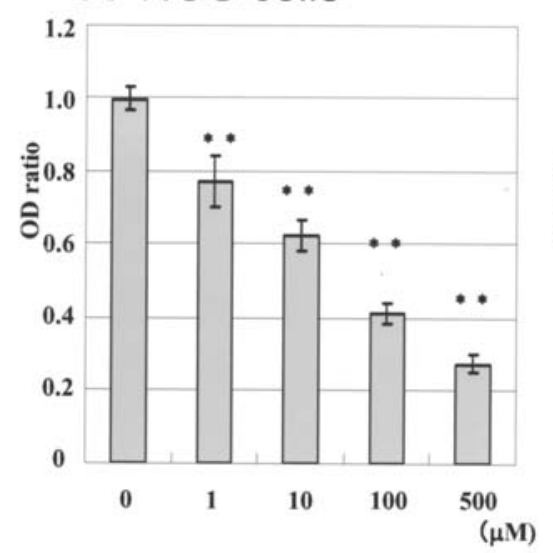

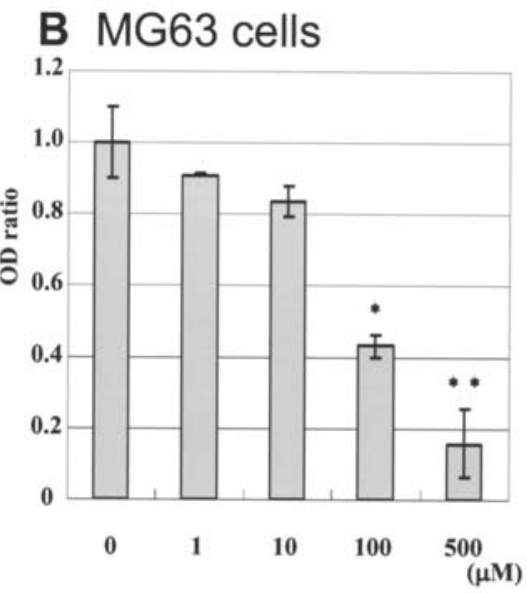

Figure 1. Dose-dependent, zoledronate-induced inhibition of human HOS and MG63 cell proliferation. HOS (A) and MG63 (B) cells were incubated with zoledronate at the indicated concentration for $48 \mathrm{~h}$ followed by MTS assay. The assays were performed in triplicate and vertical bars represent the SD. The asterisks represent statistically significant differences compared to controls $\left({ }^{*} \mathrm{P}<0.05,{ }^{* *} \mathrm{P}<0.01\right)$.

A. HOS cells

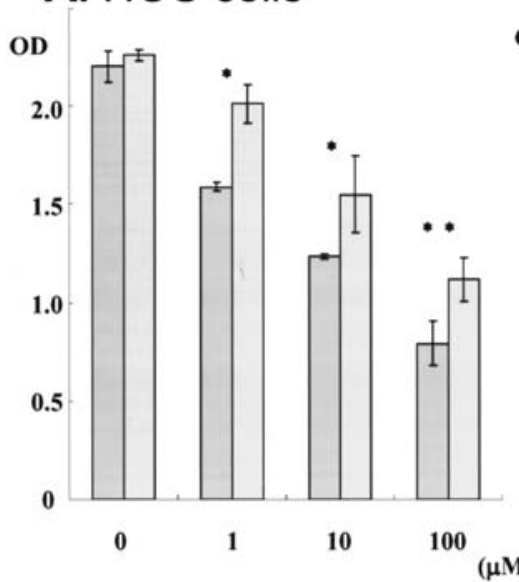

B. MG63 cells

OD

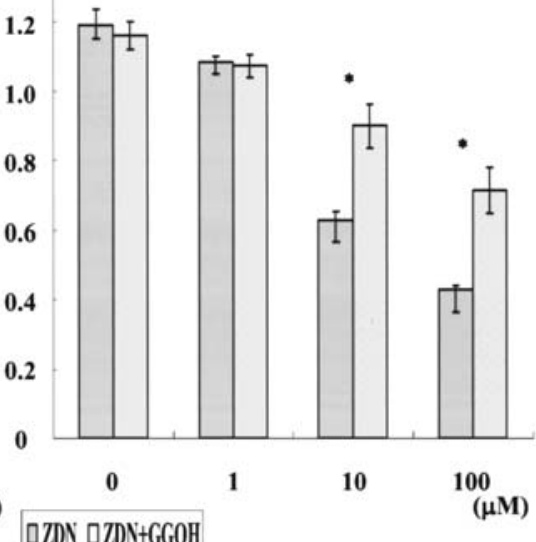

Figure 2. Effect of GGOH on the inhibitory effects of zoledronate. HOS (A) and MG63 (B) cells were pretreated with or without $20 \mu \mathrm{M}$ GGOH for $1 \mathrm{~h}$, followed by incubation with zoledronate for $48 \mathrm{~h}$. The assays were performed in triplicate and vertical bars represent the SD. The asterisks represent statistically significant differences compared to controls $\left({ }^{*} \mathrm{P}<0.05,{ }^{* *} \mathrm{P}<0.01\right)$.

osteosarcoma cell lines, HOS and MG63, in a dose-dependent manner (Fig. 1). We have previously reported that the mevalonate pathway is critical for bisphosphonate-induced apoptosis in myeloma cells (7). Isoprenylation, which is one of the post-translational modifications, is required for small $\mathrm{G}$ proteins such as cdc42, rho and rac, to reveal their kinase activities $(20,21)$. GGOH is converted to GGPP to isoprenylate the substrates in the cells. The pretreatment of HOS cells with $20 \mu \mathrm{M} \mathrm{GGOH}$ partially, but significantly, rescued the zoledronate-induced inhibition of both HOS and MG63 cell proliferation (Fig. 2), indicating that isoprenylation is involved in the inhibitory effects of zoledronate in osteosarcoma cells.

Induction of apoptosis and $S$ phase cell cycle arrest by zoledronate. Suppression of cell numbers can be achieved by inducing apoptosis and/or inhibiting cellular proliferation. Therefore, we analyzed apoptosis by flow cytometry in HOS cells using FITC-conjugated annexin V and PI. Zoledronate induced apoptosis in HOS cells in a dose-dependent manner (Fig. 3). In the preliminary experiments using unsynchronized HOS cells, we found that zoledronate induced intra-S phase cell cycle arrest (data not shown). To analyze the cell cycle precisely, HOS cells were synchronized in G1 phase by double thymidine block (Fig. 4). In control cells, the percentage of cells in $\mathrm{S}$ phase was $6.8 \%(0 \mathrm{~h}), 32.0 \%(3 \mathrm{~h}), 85.6 \%(6 \mathrm{~h})$, $31.3 \%(9 \mathrm{~h}), 14.6 \%(12 \mathrm{~h})$ and $48.8 \%(24 \mathrm{~h})$ after release of thymidine block, respectively (Fig. 4A). In contrast, most of the zoledronate-treated HOS cells were kept in S phase for up to $24 \mathrm{~h}: 6.8 \%(0 \mathrm{~h}), 67.9 \%(3 \mathrm{~h}), 87.8 \%(6 \mathrm{~h}), 94.2 \%$ (9 h), $92.8 \%$ (12 h) and $78.9 \%$ (24 h) (Fig. 4B), indicating that intra-S phase cell cycle arrest was induced by zoledronate. Similar intra-S phase arrest was observed in another osteosarcoma cell line, MG63, after treatment with $10 \mu \mathrm{M}$ zoledronate (data not shown). 


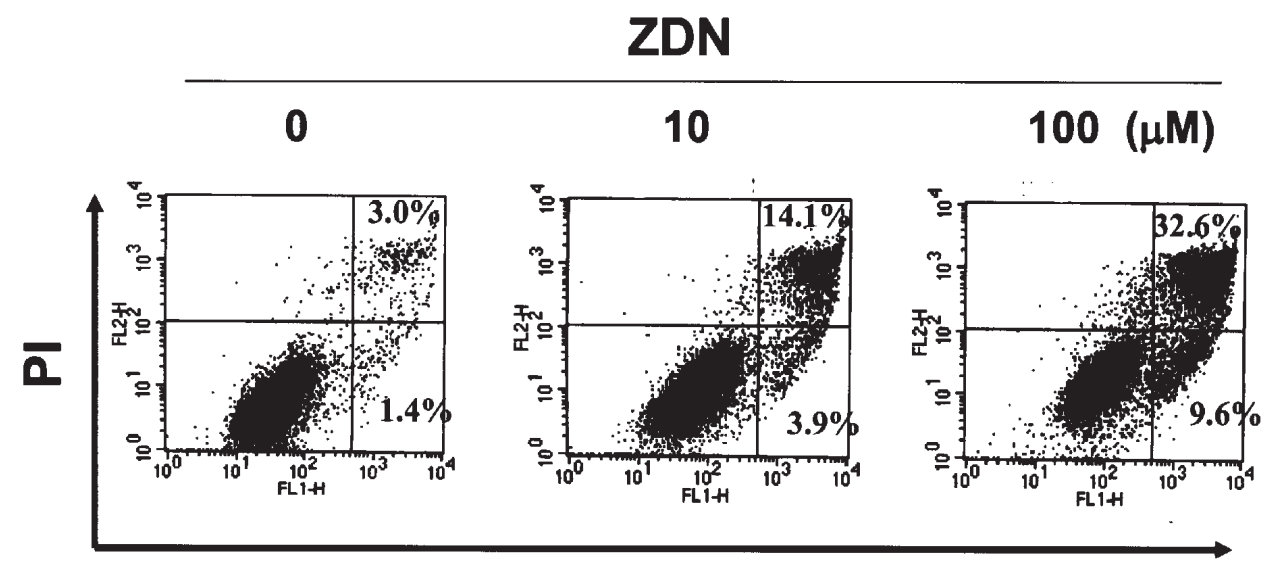

FITC-annexin V

Figure 3. Zoledronate-induced apoptosis of HOS cells. HOS cells were incubated with 0,10 or $100 \mu \mathrm{M}$ zoledronate (ZDN) for $48 \mathrm{~h}$, followed by annexin V/PI assay to detect the cells in early apoptosis (annexin $\mathrm{V}^{+} / \mathrm{PI}$ ) and late apoptosis/necrosis (annexin $\mathrm{V}^{+} / \mathrm{PI}^{+}$).

\section{A Control}

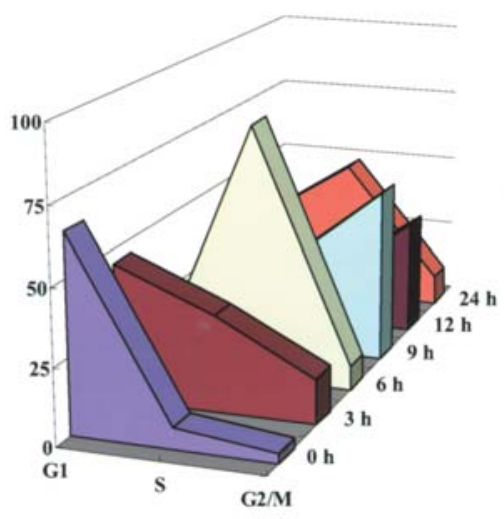

B ZDN

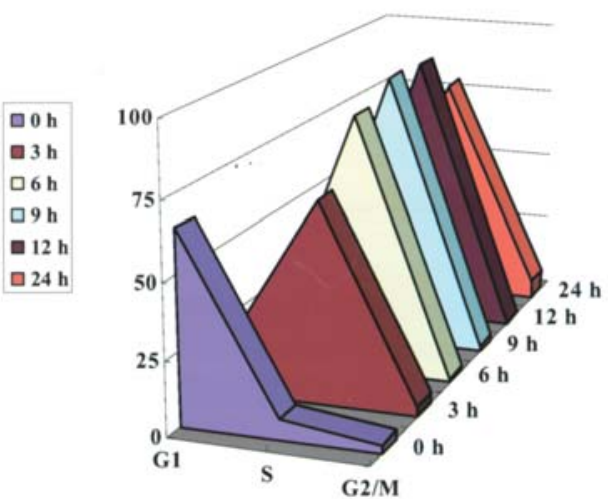

Figure 4. Zoledronate-induced arrest of HOS cells in S phase. HOS cells were synchronized in G1 phase by double thymidine block, followed by treatment with zoledronate (ZDN). HOS cells were subjected to cell cycle analysis after treatment with or without $10 \mu \mathrm{M}$ zoledronate for the indicated time. The percentage of cells in G1,S and G2/M phase is shown in the graph and the text. Each experiment was repeated three times and representative results are shown.

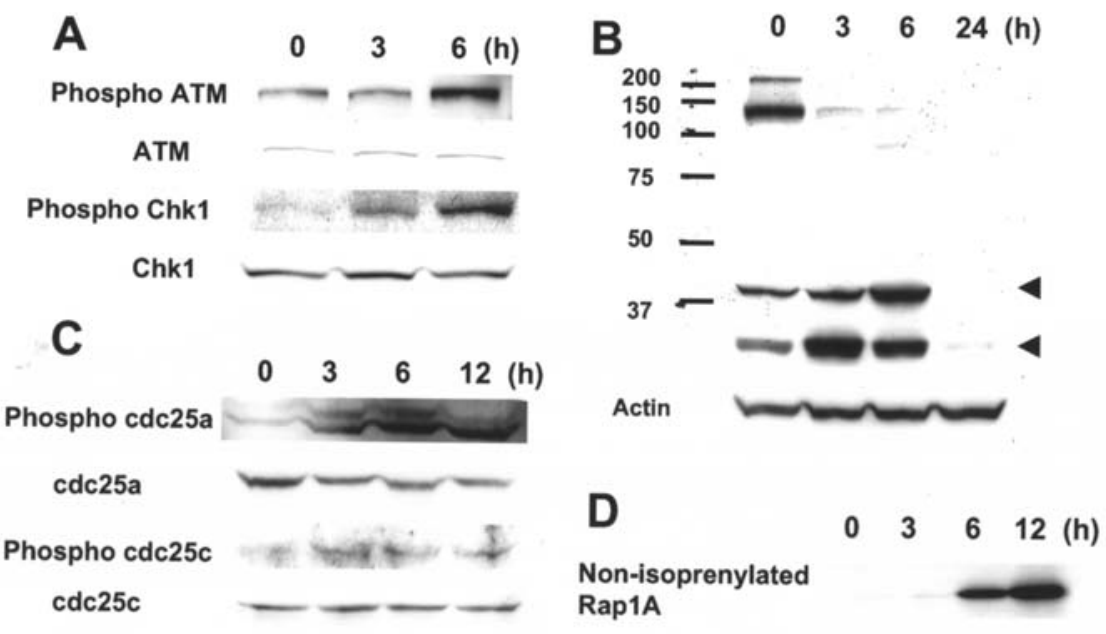

Figure 5. Intracellular signaling by zoledronate. (A) Phosphorylation of ATM and Chk1 was detected with phospho-specific antibodies by Western blotting of HOS cells after stimulation with zoledronate. The same membrane was re-probed with anti-ATM and Chk1 antibodies, respectively, to confirm equal protein loading. (B) Phosphorylation of ATM/ATR substrates (40 and $34 \mathrm{kDa}$ ) was detected with specific antibodies (upper panel). The same membrane was reprobed with anti-actin antibody (lower panel). (C) Phosphorylation of cdc25a (Thr506) and cdc25c (Ser216) was detected with each phospho-specific antibody. Each membrane was re-probed with anti-cdc25a and cdc25c antibody to confirm equal protein loading. (D) Non-isoprenylated Rap1A protein was detected with specific antibodies in HOS cells after treatment with zoledronate. 


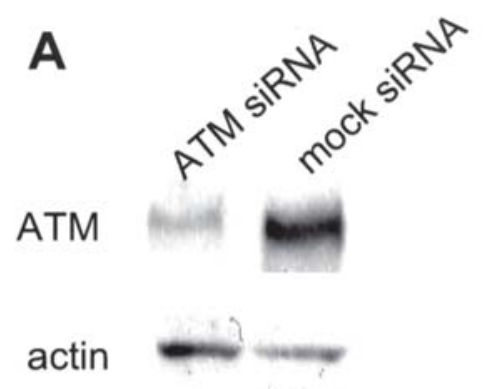

B mock siRNA
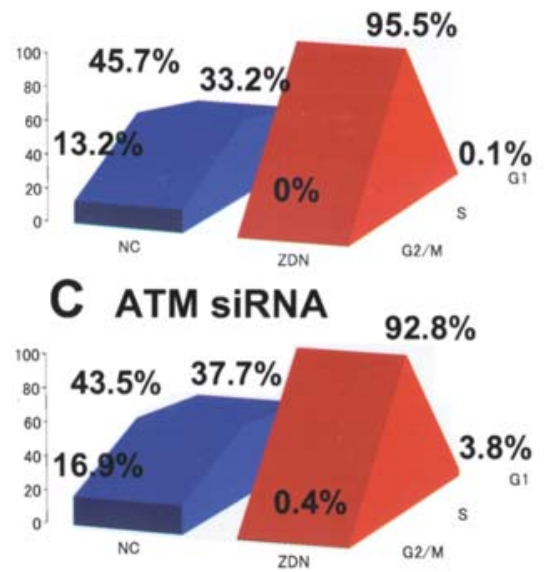

Figure 6. ATM knock down by siRNA in HOS cells. (A) Protein expression of ATM and actin in HOS cells was analyzed by Western blotting $48 \mathrm{~h}$ after transfection with ATM siRNA or mock siRNA. (B and C) HOS cell cycle after transfection with siRNA. Zoledronate at $10 \mu \mathrm{M}$ induced S phase arrest in HOS cells treated with mock siRNA and ATM siRNA, respectively. NC, negative control, in which ATM-knocked down HOS cells were treated with PBS; ZDN, zoledronate.

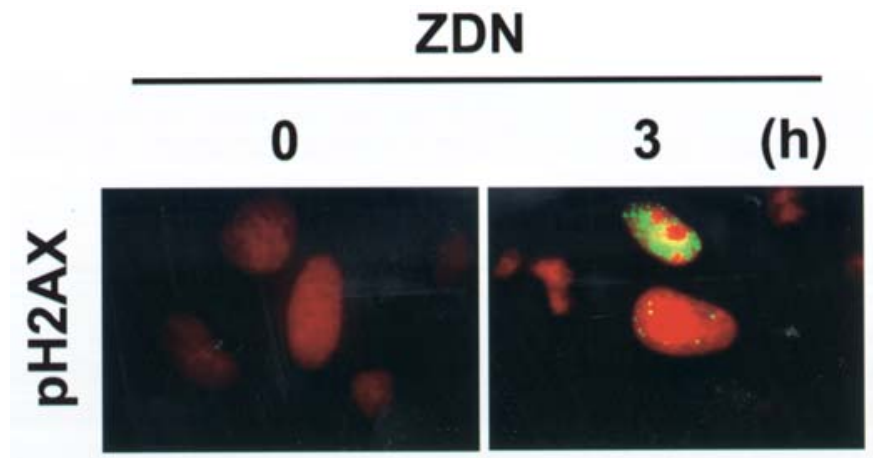

Figure 7. Nuclear foci pattern of phosphorylated $\mathrm{H} 2 \mathrm{AX}$ in zoledronate-treated HOS cells. Phosphorylated H2AX protein ( $\mathrm{pH} 2 \mathrm{AX})$ in HOS cells was stained with the specific antibody $3 \mathrm{~h}$ after treatment with $100 \mu \mathrm{M}$ zoledronate (ZDN). Nuclear foci of staining for pH2AX (green) were observed. Nuclei were stained with PI (red).
Involvement of the ATM/Chk1/cdc25 pathway. To understand the mechanisms of zoledronate-induced $\mathrm{S}$ phase arrest, we studied intracellular signaling using Western blotting (Fig. 5). There are several key molecules which induce $S$ phase arrest in mammalian cells. Phosphatidyl inositol 3 kinase (PI3K)related ATM and ATR work as sensors to detect DNA damage and replication errors. Chk1 and Chk2 kinases are serine/ threonine kinases, which are phosphorylated by ATR and ATM, and are known to inhibit the function of cde25 phosphatases by their phosphorylation. Cdc 25 phosphatases lose their function to activate cdk2 and cdc2 when cdc 25 is phosphorylated by Chk1/2 kinases, followed by $\mathrm{S}$ phase arrest. We found that $10 \mu \mathrm{M}$ zoledronate induced phosphorylation of ATM and Chk1 kinase in HOS cells (Fig. 5A).
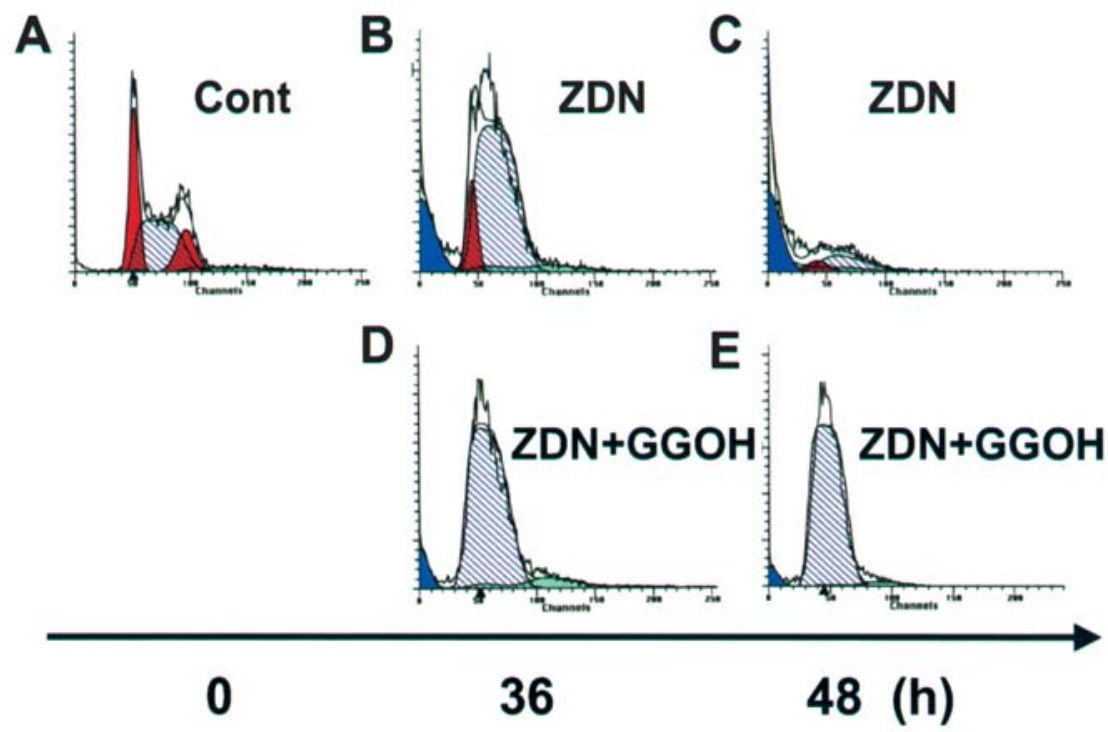

Figure 8. Cell cycle analysis of unsynchronized HOS cells. HOS cells were treated with PBS (Cont) or $100 \mu \mathrm{M}$ zoledronate (ZDN) for 0, 36 and 48 h (A-C). In some experiments, HOS cells were pre-treated with $20 \mu \mathrm{M} \mathrm{GGOH}$ for $1 \mathrm{~h}$ (D and E). Cell cycle analysis was performed using flow cytometry with Modfit software for cell cycle analysis. 
Since the amount of Chk2 was too low, we could not evaluate phosphorylation of Chk2 protein in HOS cells (data not shown). Antibodies specific for phosphorylated ATM/ATR substrates detected 40 and $34 \mathrm{kDa}$ proteins (Fig. 5B), also supporting the hypothesis that ATM and ATR are activated in HOS cells by zoledronate. As described in Materials and methods, this phospho-ATM/ATR substrate-specific antibody detects phosphorylated serine or threonine in the $\mathrm{S}^{*} / \mathrm{T}^{*} \mathrm{Q}$ motif, which is an essential requirement for the substrates of ATM/ATR. Zoledronate also induced phosphorylation of cdc25a in HOS cells (Fig. 5C). Phosphorylation of cdc25c by zoledronate was marginal in HOS cells (Fig. 5C). Non-isoprenylated Rap1A was increased by zoledronate, indicating that isoprenylation was inhibited in HOS cells (Fig. 5D).

Downregulation of ATM protein by siRNA in HOS cells. As zoledronate activated the ATM/Chk1/cdc25 pathway, we knocked down the expression of ATM protein using siRNA to analyze its function in zoledronate-induced $S$ phase arrest in HOS cells. The expression of ATM protein was clearly decreased in HOS cells by ATM siRNA, but not by mock siRNA (Fig. 6A). Zoledronate induced S phase arrest in transfected HOS cells with ATM siRNA (Fig. 6C), to a similar extent as in the cells with mock siRNA (Fig. 6B). When we knocked down the expression of ATR protein using siRNA in HOS cells, the cells did not survive (data not shown). Therefore, the roles of ATR protein in zoledronateinduced S phase arrest and apoptosis in HOS cells remain to be elucidated.

Immunostaining of phosphorylated $\mathrm{H} 2 \mathrm{AX}$ protein. To evaluate whether zoledronate induces DNA damage before $S$ phase arrest, we stained HOS cells with the specific antibody against phosphorylated H2AX protein $(\gamma-\mathrm{H} 2 \mathrm{AX})$ (Fig. 7). Following 3-h stimulation with $100 \mu \mathrm{M}$ zoledronate, $\gamma$-H2AX displayed nuclear foci in HOS cells (Fig. 7), indicating that zoledronate induced DNA double strand breaks. Doxorubicin was used as a positive control and displayed a similar nuclear staining pattern for $\gamma-\mathrm{H} 2 \mathrm{AX}$ in HOS cells (data not shown).

GGOH treatment did not prevent zoledronate-induced $S$ phase arrest, but apoptosis. When unsynchronized HOS cells were treated with $100 \mu \mathrm{M}$ zoledronate for $36 \mathrm{~h}, 85.7 \%$ of the cells were in S phase (Fig. 8B). Around $34.2 \%$ of HOS cells were in sub-G1 phase $48 \mathrm{~h}$ after treatment with zoledronate, indicating that they were in a state of apoptosis (Fig. 8C). When HOS cells were pretreated with $20 \mu \mathrm{M}$ GGOH for $1 \mathrm{~h}$, almost all the cells remained in S phase at 36 and $48 \mathrm{~h}$ after treatment with zoledronate (Fig. 8D and E). These results indicate that isoprenylation is critical for zoledronate-induced apoptosis, but not for $\mathrm{S}$ phase arrest in HOS cells.

\section{Discussion}

We have previously reported that the third-generation bisphosphonates incadronate and YM529 induce apoptosis and intra-S phase cell cycle arrest through the mevalonate pathway in human myeloma cells (7). Protein isoprenylation of small GTP-binding proteins (Ras, Rho, Rac and Rap1A) is important for regulation of the cytoskeleton and mitosis (25). In the present study, we demonstrated that zoledronate increased non-isoprenylated Rap1A in HOS cells, and GGOH prevented zoledronate-induced apoptosis, indicating that isoprenylation is involved in the signaling of zoledronate in HOS cells.

There are several new findings in the present study about bisphosphonate-induced intracellular signaling. We confirmed that phosphorylation of ATM, Chk1 and cdc25a was induced by zoledronate in HOS cells. When cdc25 phosphatases were phosphorylated by Chk1 at their serine/threonine residues, they lost their ability to dephosphorylate the tyrosine residue of cdk2 and cdc2, and this was accompanied by $\mathrm{S}$ phase arrest. These results are compatible with a previous report that resveratrol causes $S$ phase arrest in human ovarian cancer cells through the ATM/Chk/cde25c pathway (26). Zoledronate-induced DNA damage was confirmed by staining of $\gamma$-H2AX in HOS cells. To the best of our knowledge, this is the first report to demonstrate zoledronate-induced DNA damage accompanied by activation of the ATM/Chk1/cdc25 pathway.

ATM-knocked down HOS transfectants still accumulated in S phase, we speculated that ATM-related ATR is also involved as an alternative pathway in zoledronate-treated HOS cells. To elucidate the role of ATR, we studied the effects of both siRNA for ATR and ATM/ATR inhibitor caffeine; however, we could not reach a conclusion since both siRNA for ATR and caffeine alone induced cell death in HOS cells. The roles of ATR in zoledronate-induced S phase arrest in HOS cells remain to be clarified in further studies.

In conclusion, we have successfully demonstrated that zoledronate induces DNA damage and $\mathrm{S}$ phase arrest in human osteosarcoma cell lines, accompanied by activation of ATM/Chk1/cdc25 pathway. These findings may contribute to understanding the anti-neoplastic mechanisms of zoledronate.

\section{References}

1. Marina N, Gebhardt M, Teot L and Gorlick R: Biology and therapeutic advances for pediatric osteosarcoma. Oncologist 9: 422-441, 2004.

2. Nagarajan R, Chohisy D and Weigel B: New paradigms for therapy for osteosarcoma. Curr Oncol Rep 7: 410-414, 2005.

3. Mintz MB, Sowers R, Brown KM, et al: An expression signature classifies chemotherapy-resistant pediatric osteosarcoma. Cancer Res 65: 1748-1754, 2005.

4. Lipton A: Toward new horizons: the future of bisphosphonate therapy. Oncologist 9 (Suppl. 4): 38-47, 2004.

5. Clezardin P, Ebetino FH and Fournier PG: Bisphosphonates and cancer-induced bone disease: beyond their antiresorptive activity. Cancer Res 65: 4971-4974, 2005

6. Shipman CM, Rogers MJ, Apperley JF, Russell RG and Croucher PI: Bisphosphonates induce apoptosis in human myeloma cell lines: a novel anti-tumour activity. Br J Haematol 98: 665-672, 1997.

7. Iguchi T, Miyakawa Y, Yamamoto K, Kizaki M and Ikeda Y: Nitrogen-containing bisphosphonates induce S-phase cell cycle arrest and apoptosis of myeloma cells by activating MAPK pathway and inhibiting mevalonate pathway. Cell Signal 15: 719-727, 2003.

8. Senaratne SG, Pirianov G, Mansi JL, Arnett TR and Colston KW: Bisphosphonates induce apoptosis in human breast cancer cell lines. Br J Cancer 82: 1459-1468, 2000.

9. Lee MV, Fong EM, Singer FR and Guenette RS: Bisphosphonate treatment inhibits the growth of prostate cancer cells. Cancer Res 61: 2602-2608, 2001. 
10. Tassone $\mathrm{P}$, Tagliaferri $\mathrm{P}$, Viscomi $\mathrm{C}$, et al: Zoledronic acid induces antiproliferative and apoptotic effects in human pancreatic cancer cells in vitro. Br J Cancer 88: 1971-1978, 2003.

11. Alvarez E, Westmore M, Galvin RJ, et al: Properties of bisphosphonates in the 13762 rat mammary carcinoma model of tumorinduced bone resorption. Clin Cancer Res 9: 5705-5713, 2003.

12. Corey E, Brown LG, Quinn JE, et al: Zoledronic acid exhibits inhibitory effects on osteoblastic and osteolytic metastases of prostate cancer. Clin Cancer Res 9: 295-306, 2003.

13. Zhang H, Yano S, Miki T, et al: A novel bisphosphonate minodronate (YM529) specifically inhibits osteolytic bone metastasis produced by human small-cell lung cancer cells in NK-cell depleted SCID mice. Clin Exp Metastasis 20: 153-159, 2003.

14. Van der Pluijm G, Vloedgraven H, van Beek E, van der WeePals L, Lowik C and Papapoulos S: Bisphosphonates inhibit the adhesion of breast cancer cells to bone matrices in vitro. J Clin Invest 98: 698-705, 1996.

15. Boissier S, Ferreras M, Peyruchaud O, et al: Bisphosphonates inhibit breast and prostate carcinoma cell invasion, an early event in the formation of bone metastases. Cancer Res 60: 2949-2954, 2000.

16. Fromigue O, Lagneaux L and Body JJ: Bisphosphonates induce breast cancer cell death in vitro. J Bone Miner Res 15: 2211-2221, 2000.

17. Senaratne SG, Mansi JL and Colston KW: The bisphosphonate zoledronic acid impairs Ras membrane localisation and induces cytochrome $\mathrm{c}$ release in breast cancer cells. Br J Cancer 86: 1479-1486, 2002.

18. Kunzmann V, Bauer E, Feurle J, Weissinger F, Tony HP and Wilhelm M: Stimulation of gammadelta T cells by aminobisphosphonates and induction of antiplasma cell activity in multiple myeloma. Blood 96: 384-392, 2000.
19. Das H, Wang L, Kamath A and Bukowski JF: Vgamma2Vdelta2 T-cell receptor-mediated recognition of aminobisphosphonates. Blood 98: 1616-1618, 2001.

20. Coxon FP, Helfrich MH, Van't Hof R, et al: Protein geranylgeranylation is required for osteoclast formation, function, and survival: inhibition by bisphosphonates and GGTI-298. J Bone Miner Res 15: 1467-1476, 2000.

21. Cordle A, Koenigsknecht-Talboo J, Wilkinson B, Limpert A and Landreth G: Mechanisms of statin-mediated inhibition of small G-protein function. J Biol Chem 280: 34202-34209, 2005.

22. Miyakawa $\mathrm{Y}$ and Matsushime $\mathrm{H}$ : Rapid downregulation of cyclin D1 mRNA and protein levels by ultraviolet irradiation in murine macrophage cells. Biochem Biophys Res Commun 284: 71-76, 2001

23. Sawafuji K, Miyakawa Y, Weisberg E, Griffin JD, Ikeda Y and Kizaki M: Aminopeptidase inhibitors inhibit proliferation and induce apoptosis of K562 and STI571-resistant K562 cell lines through the MAPK and GSK-3beta pathways. Leuk Lymphoma 44: 1987-1996, 2003

24. Miyakawa Y, Oda A, Druker BJ, Miyazaki H, Handa M, Ohashi $\mathrm{H}$ and Ikeda Y: Thrombopoietin induces tyrosine phosphorylation of Stat 3 and Stat5 in human blood platelets. Blood 87: 439-446, 1996.

25. Caudron M, Bunt G, Bastiaens P and Karsenti E: Spatial coordination of spindle assembly by chromosome-mediated signaling gradients. Science 309: 1373-1376, 2005.

26. Tyagi A, Singh RP, Agarwal C, Siriwardana S, Sclafani RA and Agarwal R: Resveratrol causes Cdc2-tyr15 phosphorylation via ATM/ATR-Chk1/2-Cdc25C pathway as a central mechanism for S phase arrest in human ovarian carcinoma Ovcar-3 cells. Carcinogenesis 26: 1978-1987, 2005. 